\title{
Environmental Noise Implications of Quarrying at Buoho Township and Surrounding Communities in Ghana
}

\author{
Bannerman S. D. ${ }^{1}$, Osei E. M. Jnr ${ }^{2}$, Duker A. A. ${ }^{2}$, Yevugah L.L. ${ }^{2 *}$ \\ ${ }^{I}$ Materials Engineering Department, College of Engineering, Kwame Nkrumah University of Science and \\ Technology, Kumasi, Ghana \\ ${ }^{2}$ Geomatic Engineering Department, College of Engineering, Kwame Nkrumah University of Science and \\ Technology, Kumasi, Ghana
}

\author{
*Corresponding Author: Bannerman S.D., Materials Engineering Department, College of Engineering, \\ Kwame Nkrumah University of Science andTechnology, Kumasi, Ghana. \\ Email: bannerman.steve@gmail.com
}

\begin{abstract}
Due to rapid urbanization and emergence of several quarrying companies and activities within Buoho township and surrounding communities, noise levels have exceeded prescribed limits. Generation of noise largely from incessant blasting activities has become a major environmental concern for residents living in close proximity to quarry sites. This study assesses the impact of blast and ambient noise levels and its environmental health implications on susceptible individuals within exposed communities. Field observations of blast and ambient noise levels at selected locations were measured using a sound level meter. Results from blast measurements indicated a decline in noise levels as distance increased from the blast point. The highest and lowest blast noise levels recorded were $121.2 \mathrm{dBA}$ and $92.4 \mathrm{dBA}$ at distances of $203 \mathrm{~m}$ and 1340 m respectively. A comprehensive Social Impact Assessment (SIA) conducted on respondents within a 1000 meter radius from the blast point revealed that $17 \%$ always experienced noise related ailments, while $33 \%$ occasionally experienced the ailments. Finally, 50\% of respondents rarely experienced these conditions. Correlation coefficient between the field exploratory blast and social survey on noise related effects is 0.82 . This, indicates a strong relationship between blast noise levels and impact on residents within the study area.
\end{abstract}

Keywords: Buoho Township, Environmental noise, Quarrying, Noise related ailments, Social Impact Assessment.

\section{INTRODUCTION}

Quarrying is a form of land use method associated with extraction of non-fuel and non-metal minerals from rock [1]. According to Lad and Samant [2], quarrying usually involves open cast excavations from which fairly huge and deep deposits of hard or soft rocks are extracted, for production of aggregates or dimension stones using drill and blast technique. In recent years, rapid expansion of Ghana's developmental projects such as roads, schools, housing and hospitals has given rise to the establishment of many quarrying companies and has boosted the demand for building materials. Many of these companies undertake intensive exploration across the country in search of viable rock outcrops for production. Thus, communities endowed with these resources become a haven for the influx of quarrying companies. Quarrying operations gravely impact the environment in numerous ways, from exploration and blasting, transport and disposal of waste rock. Its operations usually lead to enormous disruption of the local environment, landscape alteration and generation of unproductive wastelands, dust and noise pollution, illegal stone extraction, accidents and in some areas lowering of groundwater table [2]. The intensity of this unfortunate situation is largely evident in Agyarko Buoho, Sasa and Heman Buoho communities within the study area. However, it is important to note that despite the negative effects associated with quarrying, its importance to the infrastructural and economic development of the country cannot be over emphasized. Some developmental projects established by these companies as part of their corporate social responsibilities provide relief and improvement in the livelihood of the communities [3]. 

Ghana

Quarrying companies are constantly faced with the challenge of managing major environmental impacts such as noise pollution from heavy duty drilling equipment, blasting, mobile earth moving machinery, processing plant, haulage trucks and other sources to acceptable levels that will pose minimal danger to the exposed communities [4]. Shocks and vibrations resulting from blasting activities can generate high noise levels, dust and collapse of structures within surrounding inhabited areas. Many individuals exposed to elevated noise levels as a result of incessant blasting activities are at risk of experiencing auditory and non-auditory effects. Auditory effects caused by these elevated noise levels are those associated with temporary or permanent hearing loss, while non-auditory effects are those associated with behaviour and physiology [5]. Some non-auditory effects occur as a result of greater concentration and listening effort, when living and working in a noisy environment [5]. This in turn, can lead to irritation, aggression, depression, tinnitus, headaches and disturbance in sleep patterns [6]. Aside from the psychosocial effects from community noise exposure, there is also a growing concern about its impact on public health, particularly with cardiovascular effects [7]. These cardiovascular issues may include short term changes in blood circulation involving blood pressure, heart rate, cardiac output and vasoconstriction and hormonal stress [8].

In view of these potential ailments, there has been much complaints lodged by affected individuals within Buoho Township who protest against high noise levels resulting from blasting activities by quarrying companies. Some complains often registered include legitimate claims of damage to buildings, cars and household appliances such as televisions and fridges from vibrations and fallen rocks. On the other hand, some of these damages could result from the natural setting or poor building construction [9]. Buoho Township is endowed with vast rock formations and stone hills, making it an ideal hub for stone quarrying operations. As a result, one of the most obvious environmental impact in the study area is noise, generated largely from blasting activities. Therefore, it is important to assess the immense environmental impacts resulting from quarrying activities and apply efficient management techniques needed to effectively mitigate these challenges through a well-organized structure.

This study is conducted to evaluate noise level impact from quarrying operations and other activities within the Afigya Kwabre enclave, using Buoho Township and its environs as a case study. The focus of this study is to establish a statistical correlation between blast noise levels and noise related ailments, to ascertain whether or not the duration of occupancy by residents living in close proximity to the quarry sites is a contributory factor.

\section{Materials AND Methods}

\subsection{Study Area}

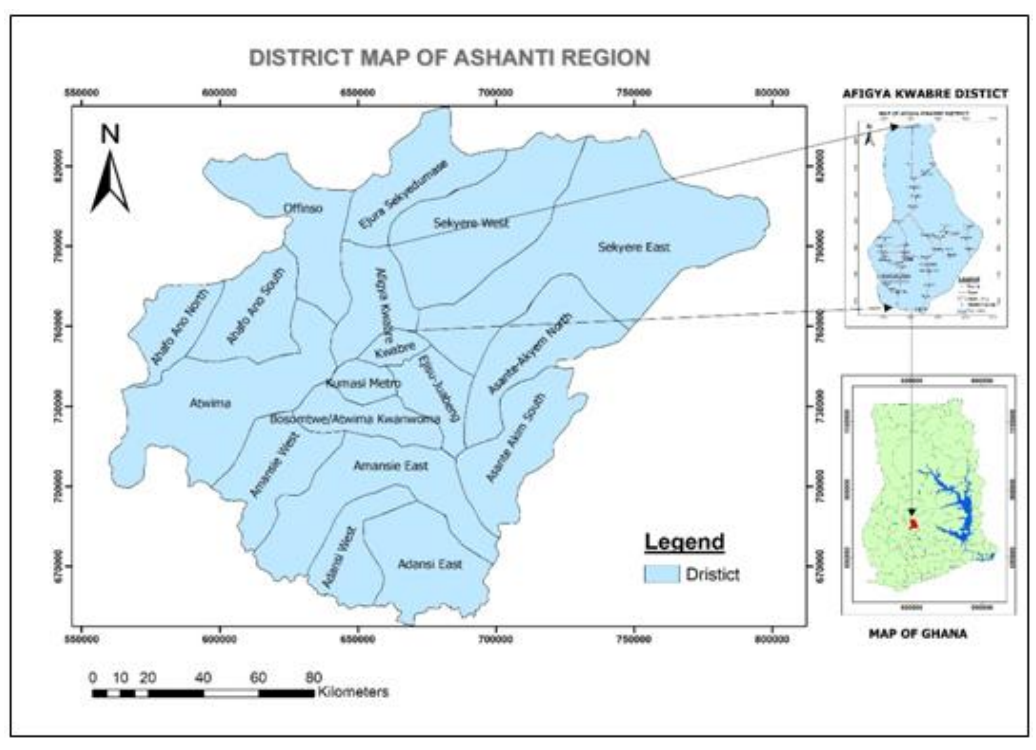

Figure1. Map of districts in Ashanti Region 


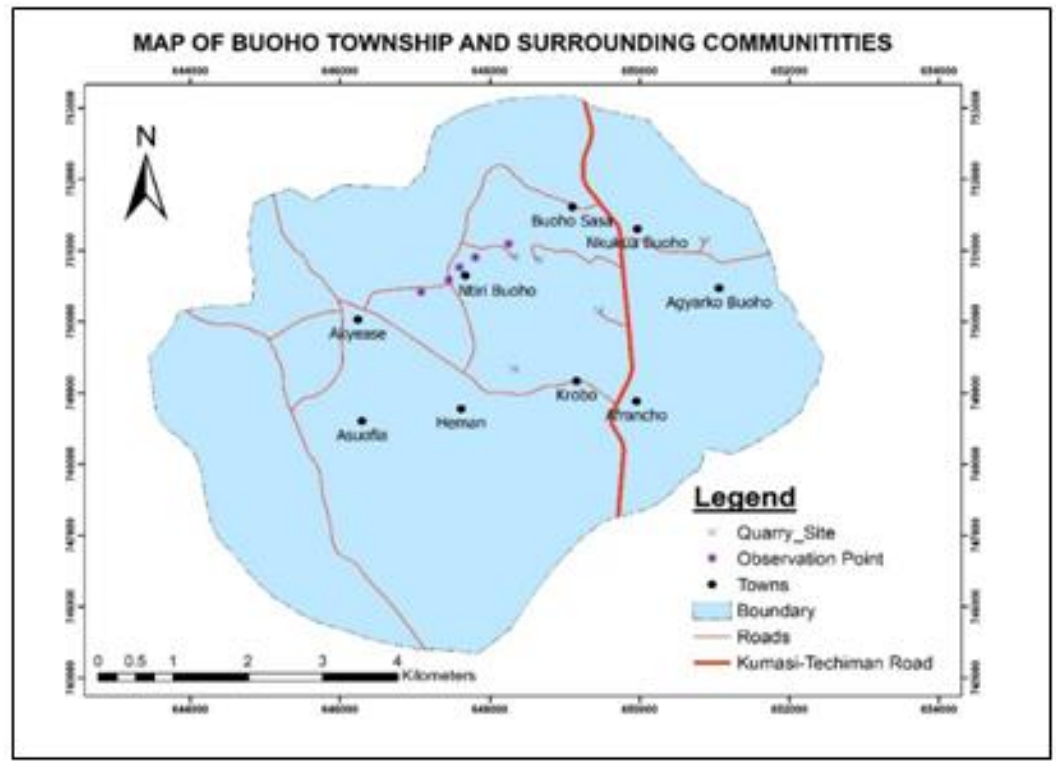

Figure2. Map of Buoho Township and surrounding communities

Buoho Township and its surrounding communities as shown in Figure 2 is located in Afigya Kwabre District of the Ashanti Region of Ghana between latitude 6045' N to 6050' N and longitude 1o38' W to 1042' W. The district shares boundary with Kumasi Metropolitan Assembly to the south, Sekyere South to the north, Offinso Municipal Assembly to the west and Kwabre District to the east as shown in Figure 1. It covers a total surface area of $342.4 \mathrm{~km} 2$, approximately $1.4 \%$ of Ashanti regional land surface area [10]. The district lies strategically in the central part of Ashanti region and along the highway from the south to the north of the country. It serves us a hub for several commercial activities [11].

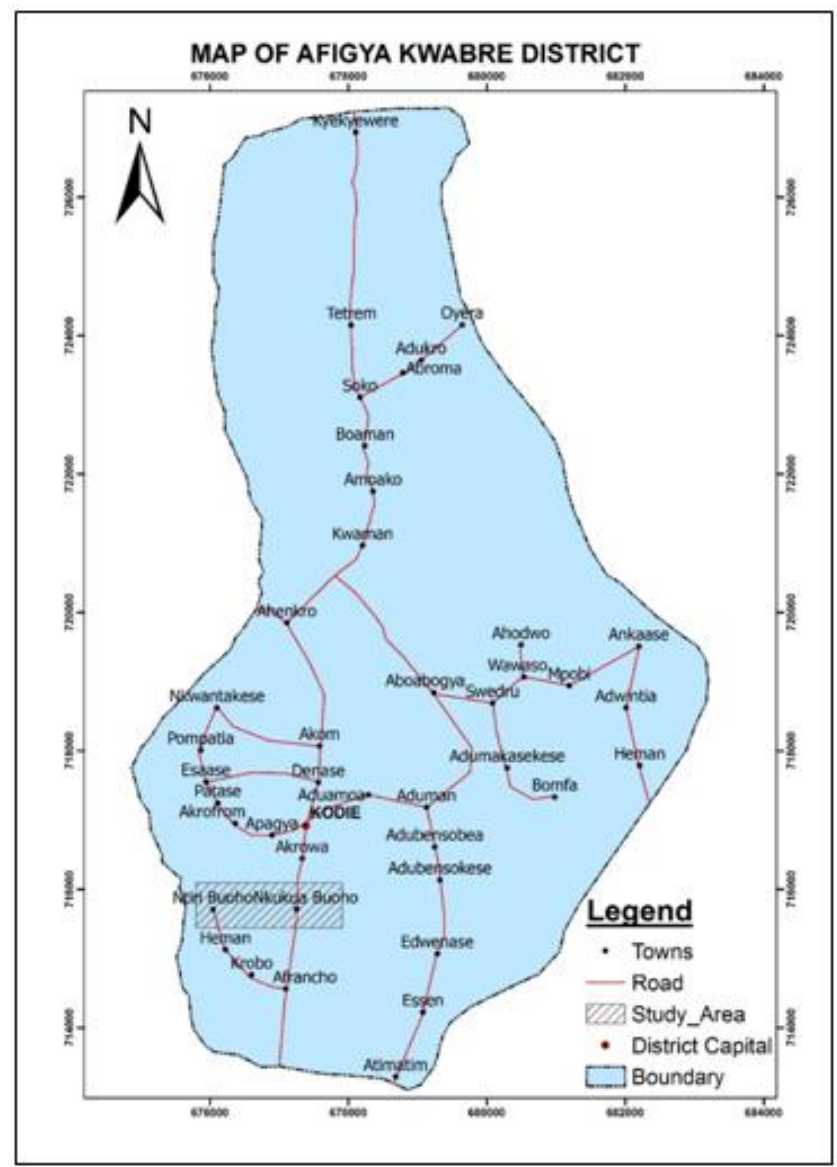

Figure3. Map of Afigya Kwabre District 

Ghana

Buoho Township lies within a dichotomized plateau, which forms part of the Mampong-Gambaga scarp with an undulating topography. Geologically, Afigya Kwabre District is made up of two distinct rock formations namely Voltaian and Dahomeyan rocks. The Dahomeyan formation consists of igneous and metamorphic rocks with gneiss and granite being dominant in areas like Nkukua Buoho, Agyarko Buoho, Ntiri Buoho and Adomako Buoho as shown in Figure 3. This has caused localities in Buoho to attract quarrying companies [11]. The land cover is mainly forestlands, which has been largely degraded by lumbering, farming, expansion of settlements and quarrying. In recent times, the closed forest consists of continuous canopy of tall and medium height trees with little or no undergrowth trees. However, the area is currently characterized by large farm patches with isolated stands of individual trees or small areas of tree clusters [12]. Commercial quarry companies in the study area extract mineral aggregate for sale to construction firms in Ghana. Irrespective of the commercial mining by these companies, a chunk of the local population is involved in small scale quarrying. Stone quarrying provides opportunities to the people of Buoho in terms of jobs and income generation [10].

\subsection{Questionnaire Administration}

A semi-structured questionnaire was self-administered, using a systematic random sampling technique to obtained firsthand information from respondents living within the operational areas of the quarrying companies. The questionnaire was designed to obtain reactions from residents and workers of the quarry companies within the study area. Section A of the questionnaire is centered on demographic details of prospective respondents, while section B is centered on the extent of blast noise effect on prospective respondents. This SIA was carried out in the localities of Nkukua Buoho, Ntiri Buoho, Heman Buoho, Afrancho Buoho, Sasa and Krobo localities to obtain subjective assessment of blast noise from residents. Sample units were selected based on proximity to quarry sites in the study area.

Out of the 75 questionnaires administered, a total of 64 responses were obtained due to lack of collaboration from the prospective respondents, fear of persecution and other personal reasons [13]. Responses for noise related effects were rated according to the level of affirmation of experience from respondents $[14,15]$. These ratings were grouped into strongly agree (SA), agree (A), disagree (D) and strongly disagree (SD) $[14,16]$. Using statistical analysis, weighted mean $(\overline{5)}$ was deduced from the responses as shown in the equation below [17]:

$\bar{X}=\frac{w_{1} X_{1}+w_{2} X_{2}+\cdots+w_{n} X_{n}}{w_{1}+w_{2}+\cdots w_{n}}=\frac{\sum w X}{\sum w}$

Where: $w_{1}, w_{2}, \ldots, w_{n}$ are the weights and

$$
X_{1}, X_{2}+, \ldots, X_{n} \text { are the values. }
$$

The results of blast observations measured in A-weighted decibels (dBA), were matched against computed weighted mean of each noise related effect from the social survey responses as $\mathrm{X}$ and $\mathrm{Y}$ variables respectively. These two variables were analyzed statistically. The results obtained from the social survey and those from the sound level meter were correlated using the Pearson correlation coefficient ( $r)$. The $r$ is calculated using the equation below:

$r=\frac{n\left(\sum X Y\right)-\left(\sum X\right)\left(\sum Y\right)}{\sqrt{\left[n \sum X^{2}-\left(\sum X\right)^{2}\right]\left[n \sum Y^{2}-\left(\sum Y\right)^{2}\right]}}$

Where:

$$
\begin{aligned}
& X=\text { Variable of } X \\
& Y=\text { Variable of } Y \\
& n=\text { Number of data pairs }
\end{aligned}
$$

\subsection{Field Observations}

Field reconnaissance was done to mark out selected areas within the communities. A total of five Global Position System (GPS) locations were selected based on their proximity to cluster of houses 

Ghana

and blasting site. The average distance between the selected locations ranged from $100 \mathrm{~m}$ to $200 \mathrm{~m}$. Distances from blast point, blast and ambience noise levels, recording times and temperature prevailing during observations were recorded (Table 1).

Table1. Ambient and blast noise levels

\begin{tabular}{|l|l|l|l|l|l|}
\hline $\begin{array}{l}\text { Observation } \\
\text { Site }(\mathbf{O S})\end{array}$ & $\begin{array}{l}\text { Distance from } \\
\text { Blast Point }(\mathbf{m})\end{array}$ & $\begin{array}{l}\text { Ambient Noise } \\
\text { Level }(\mathbf{d B A})\end{array}$ & $\begin{array}{l}\text { Blast Noise Level } \\
(\mathbf{d B A})\end{array}$ & Time $(\mathbf{G M T})$ & $\begin{array}{l}\text { Temperature } \\
(\mathbf{} \mathbf{C})\end{array}$ \\
\hline 1 & 203 & 83.7 & 121.2 & $15: 51$ & 30 \\
\hline 2 & 401 & 70.4 & 115.7 & $16: 20$ & 28 \\
\hline 3 & 747 & 74.8 & 109.5 & $11: 35$ & 27 \\
\hline 4 & 936 & 58.1 & 100.6 & 14.00 & 28 \\
\hline 5 & 1340 & 50.5 & 92.4 & $15: 20$ & 28 \\
\hline
\end{tabular}

For each blast measurement, three siren signals were sounded before each blast commences. The time interval between each signal was usually between two or three minutes. This was done to sensitize workers and residents to move to safe places and alert them on the nature of activity taking place.

The digital sound level meter was calibrated before and after use to ensure the accuracy of measurements. The device was held away from the body and at a height of approximately $1.5 \mathrm{~m}$. The A weighting scale was selected by pressing the $\mathrm{A} / \mathrm{C}$ button on the equipment. This weighting scale follows the frequency sensitivity of the human ear at low levels. This is the most commonly used weighting scale, as it also predicts quite well the damage risk of the ear [18]. In this setting, the meter filters out much of the low-frequency hence ideal for environmental noise level measurements. It measures primarily in 500 to $10,000 \mathrm{~Hz}$ range [19]. On the other hand, $\mathrm{C}$ weighting scale does not discriminate against low frequencies and measures uniformly over the frequency range of 30 to $10,000 \mathrm{~Hz}$, hence ideal for monitoring sources such as engines and machinery [19]. Once the third siren was signaled the slow button on the sound level meter was pressed to gradually monitor sound sources with consistent noise levels. Immediately each blast took place, the fast button was quickly pressed, which captured the ensuing noise level. The record button on the equipment was used to record and store the registered noise. This method of operation was used for all the other selected locations.

\section{RESULTS AND DISCUSSIONS}

\subsection{Ambient and Blast Noise Levels}

Ambient noise levels recorded at 70.4 dBA, 58.1 dBA and $50.5 \mathrm{dBA}$ for Observation Sites (OS) 2, 4 and 5 respectively were fairly low. However, there were increases in ambient noise levels at observation site 1 and 3. Similarly, blast noise levels at 121.2 dBA, 115.7 dBA, 109.59 dBA, 100.6 $\mathrm{dBA}$ and $92.4 \mathrm{dBA}$ indicates a consistent reduction from OS 1 to 5 respectively. As sound travels through the atmosphere from the source to the receiver, noise levels decrease depending on ground absorption characteristics, atmospheric conditions, and presence of physical barriers such as the nature of the terrain (Figure 4).

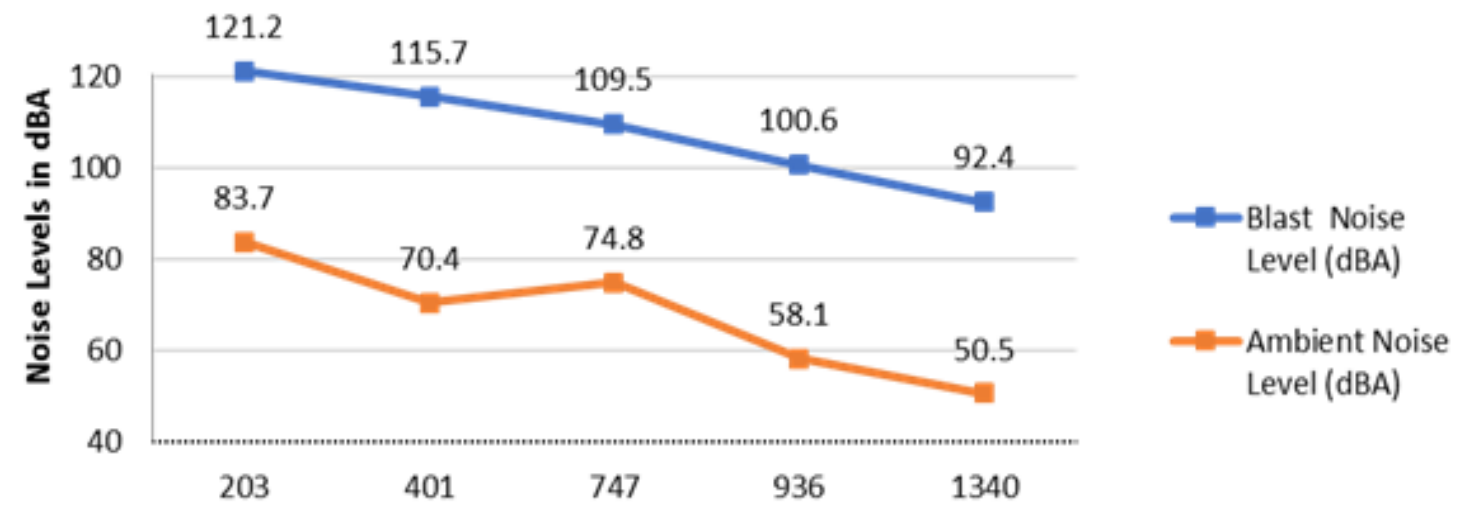

Distance from Blast Point (m)

Figure4. A graph showing the relationship between ambient noise and blast noise levels 

Ghana

Variations in noise levels at each observation site for both ambient and blast noise measurements could be as a result of several parameters including geographic landscape relief, atmospheric sound absorption, temperature, distance to the source, humidity, cloud cover, wind speed and direction [20]. Liptai et al [21] notes that sound propagation attenuates depending on the distance. Hence, for point and line sources, sound pressure is reduced by $6 \mathrm{dBA}$ or every doubled distance from it.

Ambient noise is an accumulation of noise that does not emanate from a single identifiable source. As a result, data recorded generally does not follow a specific pattern but alternates depending on the noise sources within the environs. At a distance of $203 \mathrm{~m}$ from the Blast Point (BP), the elevated ambient noise recorded $83.7 \mathrm{dBA}$ at OS 1 . This is due to milling of boulders into dimension stones and haulage by heavy duty trucks. At OS 2, which is $401 \mathrm{~m}$ the BP, ambient noise level recorded 70.4 $\mathrm{dBA}$, which was a sharp decline from what is recorded at OS 1 . This can be attributed to the number of new houses constructed within that vicinity. Most of the residents are indoors and little activities took place outdoors during the period of observation. There was also occasional passage of haulage trucks along the main road towards the quarry site.

Ambient noise levels at OS 3 of $72.4 \mathrm{dBA}$ was observed within the village center of Ntiri-Buoho at a distance of approximately $747 \mathrm{~m}$ away from the BP. The rise in ambient noise level recorded at this point can be attributed to noise emanated from children playing around, blaring music from speakers within and outside the rooms of residents and vibration from moving vehicles. OS 4 and 5 recorded lower ambient noise levels of $58.1 \mathrm{dBA}$ and $50.5 \mathrm{dBA}$ respectively. These observation sites were far away from the village center with BP at $936 \mathrm{~m}$ and $1340 \mathrm{~m}$ respectively. Few houses are scattered around this vicinity. The permissible ambient noise level for residential zone in Ghana, is $55 \mathrm{dBA}$ for day and $48 \mathrm{dBA}$ for night. Ambient noise levels recorded indicated high noise levels above the permissible limits except at OS 5.

Furthermore, blast noise measurements of $121.2 \mathrm{dBA}$ and $115.7 \mathrm{dBA}$ recorded at OS 1 and OS 2 respectively were very high, which pose serious health risk to residents. The risks increased as distance between residential homes to blast point decreased, especially at distances of $200 \mathrm{~m}$ and 400 $\mathrm{m}$. Apart from the health risks, buildings and the environment were heavily affected by dust. High blast noise at OS 1 and 2 have ground vibrations that caused buildings to shake. Debris of rocks were falling from the blasts on residential homes. The vibrations from the blast generated annoyance, fear and panic among the neighbours.

The drop in blast noise levels at distances of $747 \mathrm{~m}, 936 \mathrm{~m}$ and $1340 \mathrm{~m}$ from BP at OS 3, 4 and 5, as recorded were $109.5 \mathrm{dBA}, 100.6 \mathrm{dBA}$ and $92.4 \mathrm{dBA}$ respectively as shown above in Figure 2. The results obtained were above Environmental Protection Agency (EPA), Ghana standards of predominately heavy industry area of $70 \mathrm{dBA}$ for day and night. Also, based on Benin (2007) recommendation that induced blast noise levels should range from $115 \mathrm{dBA}$ to $120 \mathrm{dBA}$, observation recorded at OS 1 exceeded this permissible limit. As a result of the noise level dynamics recorded in this study, it can be deduced that as observation sites move farther away from the blast point into the communities towards the outskirts blast noise levels also decreases steadily. This goes to confirm the general notion that noise diminishes as distance increases from the point source [21].

\subsection{Health Impact}

Environmental noise is increasingly becoming a community concern both internationally and locally [22]. The health impact of environmental noise, largely from quarrying operation is a growing concern among both the general public and policy makers in Ghana. Prolonged exposure to these activities by individuals usually leads to noise related ailment such as ear infection and other related ailments such as asthma, pneumonia and Upper Respiratory Infection (URT) as shown below in Table 2 and Figure 5.

Table2. Outpatient morbidity returns for Afigya Kwabre district. [23]

\begin{tabular}{|l|l|l|l|l|}
\hline Case & $\mathbf{2 0 1 1}$ & $\mathbf{2 0 1 2}$ & $\mathbf{2 0 1 3}$ & $\mathbf{2 0 1 4}$ \\
\hline Ear Infection & 1260 & 1121 & 1283 & 1560 \\
\hline Asthma & 508 & 407 & 625 & 555 \\
\hline Tuberculosis & 25 & 14 & 2 & \\
\hline Pneumonia & 540 & 303 & 539 & 579 \\
\hline Upper Respiratory Tract Infections & 15411 & 15534 & 16888 & 18680 \\
\hline
\end{tabular}




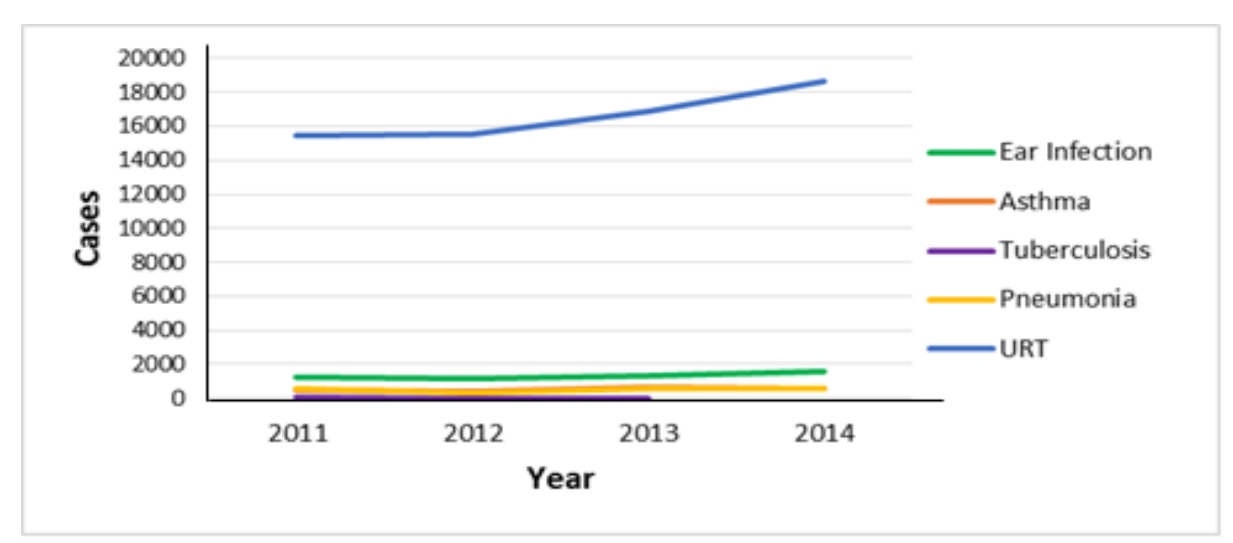

Figure5. Ear Infection and other reported cases (2011-2013) at Afigya Kwabre District

Reported cases of noise related diseases such as ear infection indicate a sharp rise in the year 2014 with 1,560 cases compared to the previous years (Figure 5). Years 2011, 2012 and 2013 recorded $1,260,1,121$ and 1,283 cases respectively. Although year 2012 showed a drop in reported cases, a sustained rise in the number of cases was observed for 2013 through to 2014. Even though, there were emergence of quarrying companies within these periods under review, a drop in number of cases in 2012 could be attributed to low demand for quarry products from customers. This means less blasting activities and subsequently low effect on surrounding communities.

Continuous increase in noise activities generated by the various quarrying companies and hauling operations by way of heavy duty trucks seem to suggest the reason for the increase in complains of ear-related diseases during these periods. Beside the noise and vibration generated after blasting, dust exposed into the atmosphere might have also caused a lot of ailments such as, asthma, pneumonia, tuberculosis and Upper Respiratory Tract (URT) infections as shown below in Table 2.

URT cases showed a sharp rise in cases from the year $2011(15,411)$ to $2014(18,680)$ as shown in Table 2. Even, though asthma recorded lower number of cases throughout the years as compared to URT infections, it revealed a rise in cases from 508 (2011) to 625 (2013), which could be attributed to the emergence of new quarry companies.

However, there was a drop in reported cases of asthma in the year 2012 (407). Similarly, this brief drop could have resulted from the low demand for quarry products from customers, thus affecting the amount of blasting activities that might have taken place during this period. The upsurge in dust related diseases, could be attributed to the lack of proper watering of various quarry sites and haulage roads in the communities. Most of these dust filled quarry premises and haulage roads are hardly watered to the detriment of residents.

\subsection{Social Impact Assessment Results}

Social Impact Assessment (SIA) results of blast noise effect on the local communities was generated through questionnaire administering. Respondents provided key information about the blast noise impact on their health. A summary of the degree of occurrence of noise related ailments experienced by respondents as a result of blasting activities is shown below in Table 3 and Figure 6. It was revealed that $17 \%$ of respondents, who live close to these quarry sites always experienced one or more noise related effects such as annoyance, tinnitus, headache, sleeplessness and cardiovascular effects, while 33\% who live a bit farther away from the sites occasionally experienced these effects. Finally, $50 \%$ of respondents who live in the remote areas from the quarry sites rarely or scarcely experienced these noise related effects as shown below in Figure 6.

Table3. Responses from residents affected by continuous exposure to blast noise

\begin{tabular}{|c|c|c|c|c|}
\hline \multirow{2}{*}{ Blast Noise Effects } & \multicolumn{4}{|c|}{ Responses } \\
\hline & $\mathbf{S A}$ & $\mathbf{A}$ & D & SD \\
\hline Annoyance & 26 & 18 & 12 & 8 \\
\hline Tinnitus & 2 & 21 & 29 & 12 \\
\hline Headache & 6 & 33 & 14 & 11 \\
\hline Sleeplessness & 3 & 19 & 31 & 11 \\
\hline Cardiovascular effect & 2 & 3 & 44 & 15 \\
\hline
\end{tabular}




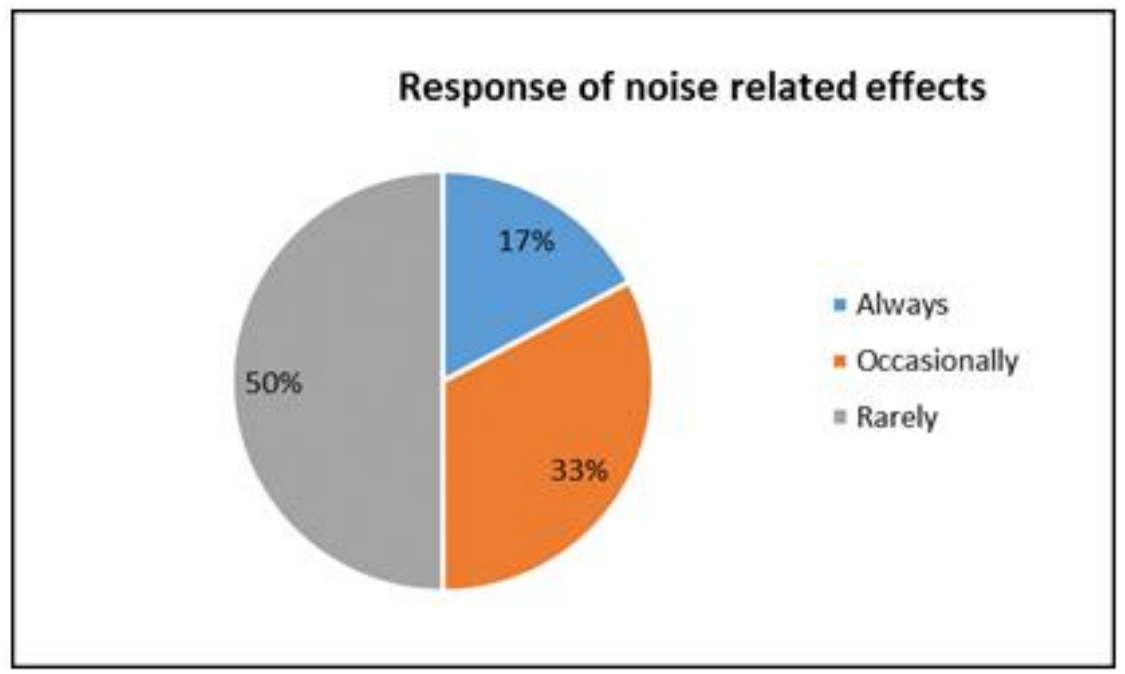

Figure6. Degree of occurrences of noise related ailments

Similarly, it was revealed that out of the total number of respondents (64), 26 strongly agreed while 18 agreed to the assertion that they are constantly annoyed by the incessant blasting activities from the quarrying companies as shown below in Table 3. They expressed their disgust for the sheer neglect of basic safe environmental practices associated with the activities such as regulated blast time for the various communities. In contrast, 12 respondents disagreed while 8 respondents strongly disagreed. These particular respondents, expressed less concern about the ongoing activities and this could be attributed to their remoteness from the blast source.

On the issue of tinnitus, 2 respondents strongly agreed while 21 agreed. These respondents attributed their affirmations to the high levels of blast noise and ground vibration that have led to continuous ringing sound in their ears. Most of these respondents live in close proximity to the blast source hence their affirmation to this ailment. However, respondents who disagreed (29) and strongly disagreed (12) attributed their assertions to the remoteness of their houses from the blast point, hence their imperviousness to this ailment.

Furthermore, it was revealed that one of the major noise related ailment constantly experienced by respondents is headache as shown above in Table 3. 6 respondents strongly agreed, while 33 agreed to this assertion. On the other hand, 14 disagreed while 11 strongly disagreed. The respondents attributed this ailment to the continuous blasting activities by the quarrying companies. They asserted that blasting usually produce high noise levels triggering these headaches and migraines. However, many of the respondents who were in disagreement to the earlier assertion revealed that they rarely experience this ailment; because their work schedule and personal activities usually takes them away from the house during blasting times.

The effect of sleep disturbance experienced by respondents as a result of the continuous blasting were quantified as strongly agreed (3) and agreed (19). Some nursing mothers expressed great difficulty in putting their babies to sleep as result of the noise levels. Those in disagreement attributed their response to the fact that they are mostly unavailable during blast times, while others indicated the remoteness of their houses from the blast source as a major contributing factor to their response. About 31 disagreed whiles 11 strongly disagreed with the experiences of sleep disturbance. Most of these respondents lived very far away from the blast source and therefore had less impact from the blasting activities.

Finally, few respondents strongly agreed (2) and agreed (3) to having developed cardiovascular ailments as a result of blast noise levels. These respondents, mostly old folks attributed this ailment to the feeling of the fear and panic anytime the blast goes off. Subsequently, causing their blood pressure, heartbeat and stress levels to rise. However, majority of respondents disagreed (44) and strongly disagreed (15) to experiencing these cardiovascular effects. These respondents were mostly young folks, as such dissented to this assertion. Also, some respondents indicated that the remoteness of their houses from the blast source, allows them to experience little or no impact from the blasting activities. 

Ghana

One of the major contributory factors to the exposure of residents to these noise related ailments is duration of occupancy in the study area. When enquired about this factor, majority of respondents (59\%) indicated that they have lived in the study area for less than 5 years, while $22 \%$ have lived for 5 to 10 years. Finally, $13 \%$ have lived for 11 to 20 years and $6 \%$ for more than 20 years as shown below in Figure 7.

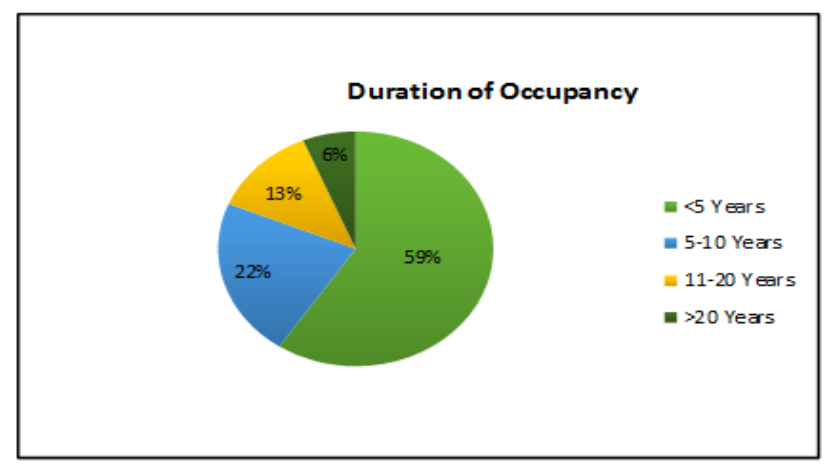

Figure7. Duration of occupancy of respondents

Residents, who have stayed in the various communities for longer periods are likely to be less susceptible to the noise related ailments than residents who have stayed for shorter periods It was found out that majority of respondents (59\%), who have lived for less than 5 years in the study area have acquired lands and erected properties close to the quarry sites, hence they are more susceptible to the aforementioned noise related ailments in this study. This occurrence could be attributed to the increase rate of migration of residents into the study area. Whereas, other respondents who have lived for 11 to 20 years $(22 \%)$ and more than 20 years $(6 \%)$ were revealed to have erected houses scattered around the outskirts and center of the villages respectively. These properties are a bit farther away from the quarry sites, thus rendering them less susceptible to the noise related ailments.

\subsection{Statistical Correlation between Blast Noise Observation and Social Survey}

Table4. Statistics of blast noise effect rating on noise related effects

\begin{tabular}{|c|c|c|c|c|c|c|}
\hline & & & & $\begin{array}{l}\text { Weighted Rating } \\
\left(\sum w x\right)\end{array}$ & $\begin{array}{l}\text { Total Ratings } \\
\left(\sum w\right)\end{array}$ & $\begin{array}{l}\text { Weighted Mean } \\
\left(\sum w x / \sum w\right)\end{array}$ \\
\hline \multicolumn{7}{|c|}{ Annoyance } \\
\hline \multicolumn{4}{|c|}{ Noise effect Ratings $(w)$} & \multirow{4}{*}{190} & \multirow{4}{*}{10} & \multirow{4}{*}{19.0} \\
\hline SA(4) & $\mathrm{A}(3)$ & $\mathrm{D}(2)$ & $\mathrm{SD}(1)$ & & & \\
\hline \multicolumn{4}{|c|}{ No. of Respondents $(x)$} & & & \\
\hline 26 & 18 & 12 & 8 & & & \\
\hline \multicolumn{7}{|c|}{ Tinnitus } \\
\hline \multicolumn{4}{|c|}{ Noise effect Ratings $(w)$} & \multirow{4}{*}{141} & \multirow{4}{*}{10} & \multirow{4}{*}{14.1} \\
\hline $\mathrm{SA}(4)$ & $\mathrm{A}(3)$ & $\mathrm{D}(2)$ & $\mathrm{SD}(1)$ & & & \\
\hline \multicolumn{4}{|c|}{ No of Respondents $(x)$} & & & \\
\hline 2 & 21 & 29 & 12 & & & \\
\hline \multicolumn{7}{|c|}{ Headache } \\
\hline \multicolumn{4}{|c|}{ Noise effect Ratings ( $w$ ) } & \multirow{4}{*}{162} & \multirow{4}{*}{10} & \multirow{4}{*}{16.2} \\
\hline $\mathrm{SA}(4)$ & $\mathrm{A}(3)$ & $\mathrm{D}(2)$ & $\mathrm{SD}(1)$ & & & \\
\hline \multicolumn{4}{|c|}{ No of Respondents $(x)$} & & & \\
\hline 6 & 33 & 14 & 11 & & & \\
\hline \multicolumn{7}{|c|}{ Sleeplessness } \\
\hline \multicolumn{4}{|c|}{ Noise effect Ratings ( $w$ ) } & \multirow{4}{*}{142} & \multirow{4}{*}{10} & \multirow{4}{*}{14.2} \\
\hline SA(4) & $\mathrm{A}(3)$ & $\mathrm{D}(2)$ & $\mathrm{SD}(1)$ & & & \\
\hline \multicolumn{4}{|c|}{ No of Respondents $(x)$} & & & \\
\hline 3 & 19 & 31 & 11 & & & \\
\hline \multicolumn{7}{|c|}{ Cardiovascular effect } \\
\hline \multicolumn{4}{|c|}{ Noise effect Ratings (w) } & \multirow{4}{*}{120} & \multirow{4}{*}{10} & \multirow{4}{*}{12.0} \\
\hline SA(4) & $\mathrm{A}(3)$ & $\mathrm{D}(2)$ & $\mathrm{SD}(1)$ & & & \\
\hline \multicolumn{4}{|c|}{ No of Respondents $(x)$} & & & \\
\hline 2 & 3 & 44 & 15 & & & \\
\hline
\end{tabular}


Environmental Noise Implications of Quarrying at Buoho Township and Surrounding Communities in Ghana

Results of the computed weighted mean for each noise related effect, is shown in Table 4. In addition, field exploratory blast noise observations and weighted mean for each noise related effect enabled correlation coefficient to be calculated as shown in Tables 5 and 6 . Mean weight ratings for the various noise related effects showed relatively high values for annoyance (19.00), tinnitus (14.10), headache (16.20), sleeplessness (14.20) and cardiovascular effects (12.00). These values show the extent to which blasting activities impact on the residents living in the study area.

Table5. Data set for correlation of blast noise and social survey.

\begin{tabular}{|c|c|}
\hline Blast Noise Observation (OS) (dBA) $(\mathbf{X})$ & Weighted Mean for Noise Related Effects (Y) \\
\hline 121.2 & 19.0 \\
\hline 115.7 & 14.1 \\
\hline 109.5 & 16.2 \\
\hline 100.6 & 14.2 \\
\hline 92.4 & 12.0 \\
\hline
\end{tabular}

Based on the variables $\mathrm{X}$ and $\mathrm{Y}$ shown above in Table 5, correlation coefficient (r) was computed using the procedure table in Microsoft Excel 2013 as shown below in Figure 8 and Table 6.

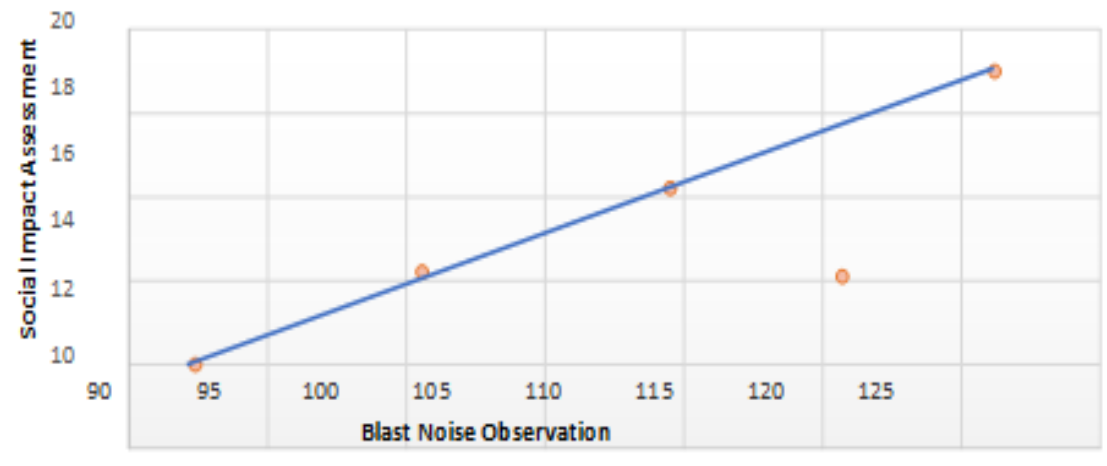

Figure8. A graph showing the correlation between blast noise levels and social survey results

Table6. Procedure table for finding correlation coefficient ( $r$ ).

\begin{tabular}{|l|l|l|l|l|l|}
\hline Data & $(\mathbf{X})$ & $(\mathbf{Y})$ & $\mathbf{X Y}$ & $\mathbf{X}^{2}$ & $\mathbf{Y}^{2}$ \\
\hline 1 & 121.20 & 190.00 & 2302.80 & 14689.44 & 361.00 \\
\hline 2 & 115.70 & 14.10 & 1631.37 & 13386.49 & 198.81 \\
\hline 3 & 109.50 & 16.20 & 1773.90 & 11990.25 & 262.44 \\
\hline 4 & 100.60 & 14.20 & 1428.52 & 10120.36 & 201.64 \\
\hline 5 & 92.40 & 12.00 & 1108.80 & 8537.76 & 144.00 \\
\hline $\boldsymbol{n}=\mathbf{5}$ & $\sum \boldsymbol{X}=\mathbf{5 3 9 . 4 0}$ & $\sum \boldsymbol{Y}=\mathbf{7 5 . 5 0}$ & $\sum \boldsymbol{X} \boldsymbol{Y}=\mathbf{8 2 4 5 . 3 9}$ & $\sum \boldsymbol{X}^{\mathbf{2}}=\mathbf{5 8 7 2 4 . 3 0}$ & $\sum \boldsymbol{Y}^{\mathbf{2}=1167.89}$ \\
\hline
\end{tabular}

$r=\frac{n\left(\sum X Y\right)-\left(\sum X\right)\left(\sum Y\right)}{\sqrt{\left[n \sum X^{2}-\left(\sum X\right)^{2}\right]\left[n \sum Y^{2}-\left(\sum Y\right)^{2}\right]}}$

$r=\frac{5(8245.39)-(539.4)(75.50)}{\sqrt{\left[5(58724.30)-(539.40)^{2}\right]-\left[5(1167.89)-(75.50)^{2}\right]}}=0.82$

\section{CONCLUSIONS AND RECOMMENDATIONS}

In assessing the environmental impact of quarrying on Buoho township and surrounding communities, it can be inferred that; demand for dimension stones have resulted in extensive uncontrolled blasting activities by the various companies. Therefore, continuous exposure to high noise levels, pose serious environmental health risk to residents living in close proximity to the quarry sites. This study has been able to deduce a statistical correlation between blast noise levels and subsequent noise related impacts on the exposed communities as shown in Figure 8. A correlation coefficient (r) of 0.82 was obtained from the analysis. A positive $\mathrm{r}$, indicates a strong correlation between blast noise observations and SIA results. In addition, duration of occupancy by both new and old residents was also found out to be a contributory factor in the susceptibility of individual's to noise related ailments. In view of these developments, headache, tinnitus and other noise related ailments mentioned in this study could be attributed to the continuous exposure of blast noise levels to workers and inhabitants who live in close proximity to the quarry sites for over a period of time. 

Ghana

In order to mitigate this environmental hazard, existing and future quarry companies within the study area should consider a 1000 meter buffer zone around quarry sites to fend off future residents from occupying these places. Structures, that are already within this buffer zone should be evaluated and compensated in order to save residents from the adverse effects of blast noise. Communities in close proximity to quarry sites should inculcate the habit of tree planting around their houses to provide some amount of noise absorption. Additionally, well planned blasting schedules must be used to notify residents before blasting activities take place. This will enable inhabitants to plan effectively against fly rocks and excessive pain from blast noise towards future blasts.

In future, further research should be done on the quantitative analysis of environmental health impact of water and dust pollution on communities within the study area.

\section{REFERENCES}

[1] Ukpong, E. C., Environmental Impact of Aggregate Mining by Crush Rock Industries in Akamkpa Local Government Area of Cross River State. Nigerian Journal of Technology. 31(2), pp. 128-138 (2012).

[2] Lad R. J., Samant J. S., Environmental and Social Impacts of Stone Quarrying-A Case Study of Kolhapur District, India. International Journal of Current Research. 6(3), pp. 5664-5669 (2014).

[3] Twumasi-Ampofo K., Osei-Tutu E., Decardi-Nelson I and Ofori, P. A., A Model for Reactivating Abandoned Public Housing Projects in Ghana. Civil and Environmental Research. 6(3), pp. 6-16 (2014).

[4] Vardhan H., Rao Y. V. and Karmakar, N., Noise Problem and its Control for Heavy Earth Moving Machinery Deployed in Opencast Mines - A Critical Review. Journal of Mines, Metals and Fuel. 52(12), pp. 360-375 (2006).

[5] Sukowski, H. Sound Acoustics for Employees (SAFE): A General Survey on Non-Auditory Effects of Noise at Work Places, Dortmund: BAuA, November 5-6; 2015.

[6] Edwards A. K., Characteristics of Noise Induced Hearing Loss in Gold Miners, Master's Thesis. Pretoria, University of Pretoria, South Africa, pp. 55 (2008).

[7] Lafferty, J. S., Potential Health Effects of Noise Exposure. (Homepage on the internet), City of Wisconsin; 2013. (Accessed February 10, 2017). Available from: http://www.publichealthmdc.com.

[8] WHO, Burden of Disease from Environmental Noise. WHO Regional Office Publication, Denmark, pp. 106 (2011).

[9] OSHA, Noise and Hearing Conservation - How to Evaluate Noise Exposure. (Homepage on the Internet), Washington, 2011. (Accessed 2015 November 7,). Available from: https://www.osha.gov/dts/osta/ otm/ noise/exposure/\#indications.

[10] Asante, F., Abass. K., Afriyie K. Stone Quarrying and Livelihood Transformation in Peri-Urban Kumasi, A Research Journal on Humanities and Social Sciences, 4(13), pp. 93 - 107(2014).

[11] Afigya Kwabre District Assembly (AKDA). Profile of Afigya Kwabre District Assembly in the Ashanti Region of Ghana, 2014. (Homepage on the Internet), Ashanti Region, 2014. (Accessed 2014 October 3). Available from: http://afigyakwabre.ghanadistricts.gov.gh.

[12] Ministry of Food and Agriculture (MOFA). Narrative Profile of Afigya Kwabre District in the Ashanti Region of Ghana, 2014. (Accessed 2014 October 3). Available from: http://mofa.gov.gh/site/page_id=828.

[13] Thayer-Hart, N., Dykema, J., Elver, K., Schaeffer, N. C., and Stevenson, J., Survey Fundamentals - A Guide to Designing and Implementing Survey. University of Wisconsin System Board of Regents, pp. 20 (2010).

[14] Likert, R. A Technique for the Measurement Attitudes, Archives of Psychology, R. S. Woodworth. (140). pp. 1- 55 (1932).

[15] Uebersax, J. S. Likert Scales: Dispelling the Confusion - Statistical Methods for Rater Agreement. (Homepage on the Internet). (Accessed 2015 September 16). Available from: http://john-uebersax.com/ stat/likert.htm.

[16] Okoro, R. C. Survey and Analysis of Noise By Generating Plants in Some Parts of the University Of Calabar, Cross River State Nigeria. International Journal of Research in Agriculture and Food Sciences, 1(3), 15pp. (2014).

[17] Bluman, A. G. Elementary Statistics-A Step by Step Approach. McGrill Hall Publishers, 7th Edition, 115pp (2007).

[18] Leight, H. Hearing Safety Glossary. (Homepage on the Internet), 2016. (Accessed 2016 December 4). Available from: http://www.howardleight.com/hearing-protection/hearing-safety-glossary. 
[19] Vernier Software and Technology (VST). What is the Difference between A Weighting and C Weighting? (Homepage on the Internet), 2016. (Accessed 2016 December 14). Available from: www. vernier.com/ til/ $3500 /$.

[20] Benin, A. K., Impact of Dimension Stone Production on the Environment: A Case Study at Granite and Marbles Company Limited, Masters Thesis, Kwame Nkrumah University of Science and Technology, Ghana, 75pp (2007).

[21] Liptai, P., Badida, M., Lukáčová, K., Influence of Atmospheric Conditions on Sound Propagation Mathematical Modeling, Óbuda University e-Bulletin, 5(1), pp. 127-34 (2015).

[22] enHealth Council, The Health Effects of Environmental Noise - other than Hearing Loss, A publication Prepared for the Department of Health and Ageing, Population Health Division, New South Wales Health Department, Australia, 71pp (2004).

[23] Afigya Kwabre District Health Directorate (AKDHD), Reported Cases of Disease in Afigya Kwabre District (2011-2014), Afigya Kwabre District Health Directorate Report, 10pp. (2014).

Citation: Bannerman S.D., Osei E.M. Jnr., Duker A.A., Yevugah L.L., "Environmental Noise Implications of Quarrying at Buoho Township and Surrounding Communities in Ghana " International Journal of Research in Environmental Science, vol. 4, no. 3, p. 1-12, 2018. http://dx.doi.org/10.20431/2454-9444.0403001

Copyright: () 2018 Authors. This is an open-access article distributed under the terms of the Creative Commons Attribution License, which permits unrestricted use, distribution, and reproduction in any medium, provided the original author and source are credited. 